\title{
DETERMINANTES DE LA RENTABILIDAD DE LOS FONDOS DE INVERSIÓN EN BOLIVIA
}

\section{Alejandro Vargas Sanchez}

\section{RESUMEN}

En el presente documento se desarrolla un análisis empírico de los factores determinantes de la rentabilidad de los Fondos de Inversión en Bolivia. A través de la estimación de un modelo de Vectores Auto Regresivos con datos de Panel y Vectores Auto Regresivos Estructurales, con datos mensuales de 36 fondos de inversión para el periodo 2012-2016, se identifican las interdependencias dinámicas entre variables económicas y el rendimiento de los Fondos de Inversión. Los resultados muestran que el incremento en la tasa de interés de depósitos a plazo fijo, la reducción en la liquidez de entidades financieras, el aumento de la actividad económica y la disminución de la inflación, tienen un efecto positivo sobre la rentabilidad de los fondos de inversión. De las variables mencionadas, la más influyente es la inflación.

Palabras Clave: Rentabilidad, Fondos de Inversión, Vectores Auto Regresivos, Datos de Panel.

DOI: $10.23881 /$ idupbo.018.2-2e 